\title{
Antarctic Bottom Water Flow through the Hunter Channel*
}

\author{
Walter Zenk, Gerold Siedler, ${ }^{+}$And Bernd LenZ \\ Institut für Meereskunde an der Universität Kiel, Kiel, Germany \\ NELSON G. HoGG \\ Woods Hole Oceanographic Institution, Woods Hole, Massachusetts
}

(Manuscript received 6 April 1998, in final form 15 October 1998)

\section{ABSTRACT}

\begin{abstract}
The Rio Grande Rise acts as a natural barrier for the equatorward flow of Antarctic Bottom Water in the subtropical South Atlantic. In addition to the Vema Channel, the Hunter Channel cuts through this obstacle and offers a separate route for bottom-water import into the southern Brazil Basin. On the occasion of the Deep Basin Experiment, a component of the World Ocean Circulation Experiment (WOCE), the expected deep flow through the Hunter Channel was directly observed for the first time by an array of moored current meters and thermistor chains from December 1992 to May 1994. Main results are (i) the Hunter Channel is, in fact, a conduit for bottom-water flow into the Brazil Basin. Our new mean transport from moored current meters [2.92 $\left.( \pm 1.24) \times 10^{6} \mathrm{~m}^{3} \mathrm{~s}^{-1}\right]$ is significantly higher than earlier estimates that were based on geostrophic calculations. (ii) During the WOCE observational period a tendency toward increased bottom-water temperatures was observed. This observation from the Hunter Channel is consistent with findings from the Vema Channel. (iii) The overflow through the Hunter Channel is highly variable and puts in perspective earlier synoptic geostrophic transport estimates.
\end{abstract}

\section{Introduction}

The Rio Grande Rise represents one of the major barriers for the equatorward spreading of bottom water in the South Atlantic. It is situated at approximately $32^{\circ} \mathrm{S}$, separating the Argentine Basin to the south from the Brazil Basin farther north (Fig. 1). It connects the continental slope regions off Santos, Brazil, with the Mid-Atlantic Ridge, similar to the Walvis Ridge extending across the eastern basin toward Africa.

Two large gaps intersect the Rio Grande Rise: near $39^{\circ} \mathrm{W}$ the Vema Channel (sill depth $4660 \mathrm{~m}$ ) and near $28^{\circ} \mathrm{W}$ the Hunter Channel $(\sim 4200 \mathrm{~m})$. They allow the export of Antarctic Bottom Water from the Argentine Basin. Some additional flow of bottom water occurs across the Lower Santos Plateaus between the Continental Rise and the Vema Channel. According to a recent study, however, based on two-year long direct cur-

\footnotetext{
* Woods Hole Oceanographic Institution Contribution Number 9720 .

+ Current affiliation: Instituto Canario de Ciencias Marinas, Telde, GC, Spain.
}

Corresponding author address: Dr. Walter Zenk, Institut für Meereskunde an der Universität Kiel, 24105 Kiel, Germany.

E-mail: wzenk@ifm.uni-kiel.de rent observations (Hogg et al. 1998), the majority of the water masses there appear to recirculate within the Brazil Basin. Due to their importance for basinwide deepwater circulation, both the Vema and the Hunter Channel flows have been investigated repeatedly during the Deep Basin Experiment (DBE) of the World Ocean Circulation Experiment (WOCE). A summary of the DBE program was given by Hogg et al. (1996).

Although the flows through both channels contribute significantly to the bottom-water exchange (Speer and Zenk 1993), earlier observations concentrated on the supposedly much larger transports in the Vema Channel (Hogg et al. 1982; Zenk et al. 1993; Speer et al. 1992). All available transport estimates of bottom-water flow through the Vema Channel seem to converge at about $4 \times 10^{6} \mathrm{~m}^{3} \mathrm{~s}^{-1}$ (Hogg et al. 1999). The first long-term current meter observations from the Hunter Channel were only recently reported by Pätzold et al. (1996) and demonstrate a second quasi-permanent northward overflow of bottom water across its eastern sill into the southeastern Brazil Basin.

Interestingly, the first indications of a substantial outflow of bottom water in the Hunter region came from a series of biological observations. Burckle and Biscaye (1971) reported diatoms of Antarctic origin, Nitschia kerguelensis, north of the Hunter Channel, which they believed could not have reached this province through 


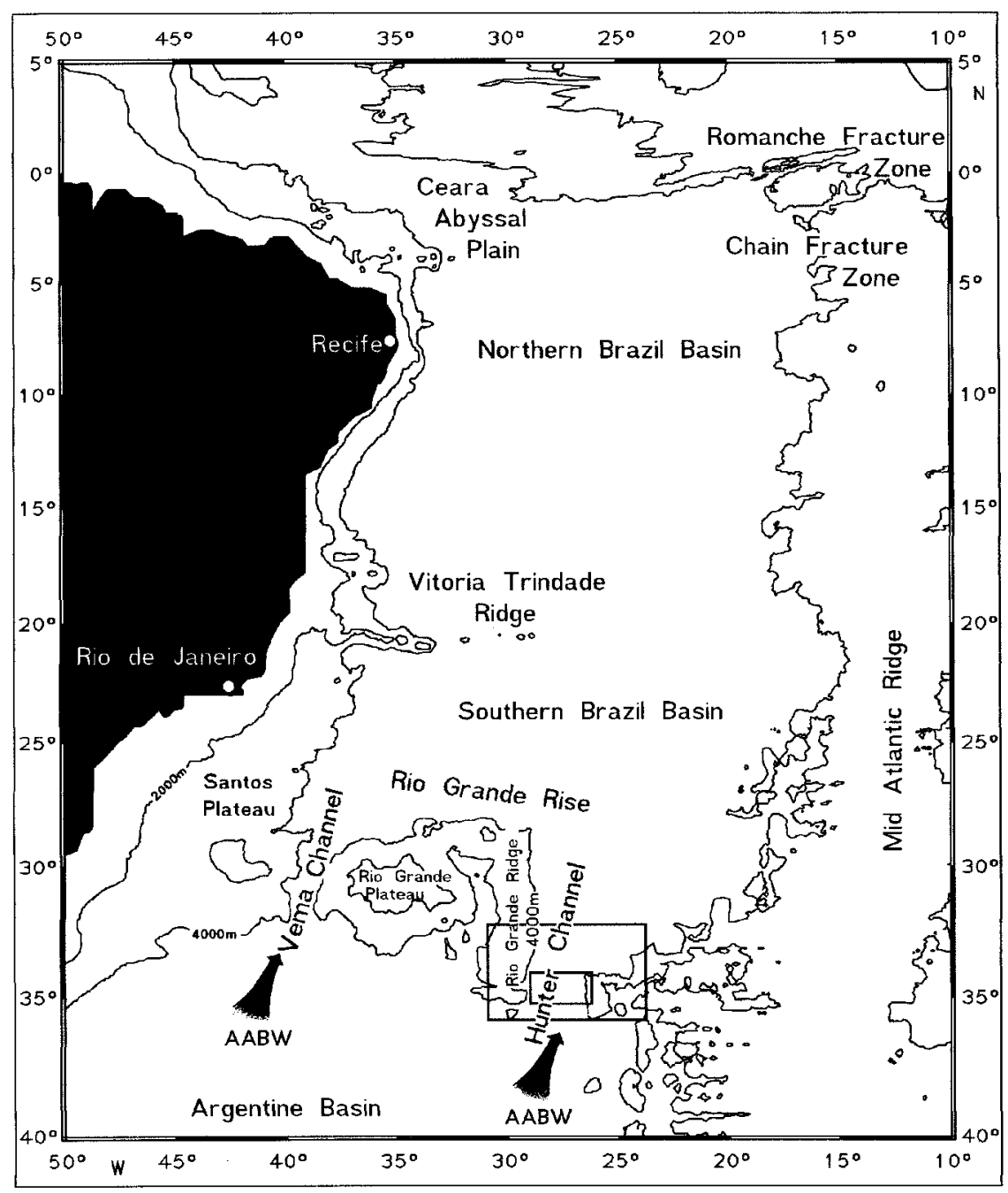

FIG. 1. Topography of the Brazil Basin and adjacent regions. The Rio Grande Rise acts as a natural obstacle for the equatorward spreading of Antarctic Bottom Water. This barrier is intersected by the Vema Channel in the west and the Hunter Channel in the east. More detailed maps of the Hunter topography are shown in Figs. 2 and 3 (Boxes). Arrows indicate the export of Antarctic Bottom Water (AABW) from the Argentine Basin.

the Vema Channel, but must have been advected through an unknown gap in the nearby topography. Later the region obtained the name "Hunter Channel" after Hunter College, "whose students had participated in search for it." This New York City college itself was named after its founding president, Thomas Hunter (Limmer 1987).

During the DBE a number of visits were paid to the Hunter Channel by FS Meteor. These cruises are documented in the following technical reports: M15-Siedler and Zenk (1992), M22—-Siedler et al. (1993), M28Zenk and Müller (1995), M34-Zenk et al. (1996). Not all cruises were equally favored by weather conditions, which sometimes prevented optimal bathymetric and hydrographic surveys. Cruises in 1992 and 1994 concentrated on the launching and retrieval of current meter moorings. All the campaigns added bathymetric information about the Hunter Channel as described in Pätzold et al. (1996). Here we present hydrographic observations from individual surveys and long-term current and temperature observations from moored instruments, which we will try to reconcile while concentrating on the bottom-water flow.

A central question of the present paper concerns the representativeness of earlier Hunter Channel transport estimates, which were inferred from sparsely distributed stations in hydrographic surveys. In section 2 we present the datasets, and in section 3 we discuss the temperature variability and geostrophic current distributions in the Hunter Channel according to hydrographic snapshots. Section 4 deals with the interpretation of the available time series. Section 5 discusses the calculation of bot- 


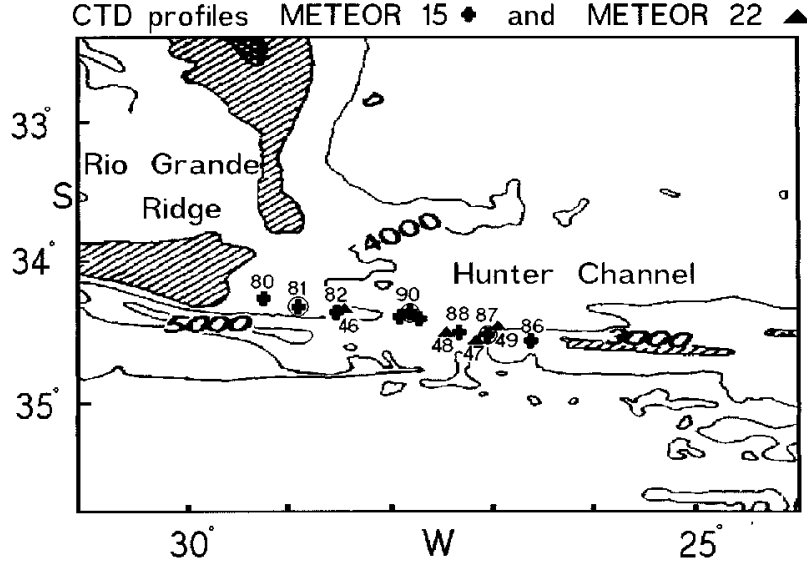

FIG. 2. Topography of the Hunter Channel according to Cherkis et al. (1989). Superimposed are hydrographic stations occupied during Meteor cruises 15 (Jan 1991) and 22 (Dec 1992). Displayed numbers indicate CTD profiles. Profile numbers in circles denote positions used for Fig. 14. Contour intervals are given in $1000 \mathrm{~m}$ steps.

tom-water transports. In the concluding section 6 we assess the inferred time series of bottom-water transports through the Hunter Channel in the light of previous observations and indicate its potential impact on the bottom water mass budget of the Brazil Basin.

\section{Dataset}

The hydrographic dataset with stations reaching the bottom of the Hunter Channel contains observations from January 1991 on Meteor cruise 15 (M15), December 1992 (M22), and May 1994 (M28). The most complete dataset originates from M15 when 10 conductivity-temperature-depth (CTD) stations were occupied. Sections of potential temperature, salinity, and potential density were earlier presented by Speer and Zenk (1993). Four CTD profiles were obtained during M22 when the Hunter mooring array was deployed. The recovery cruise M28 provided five CTD stations in the central Hunter Channel. The spatial distribution of these data is given in Figs. 2 and 3a. The quality of all CTD data is close to the WOCE Hydrographic Program standards. Accuracies are better than $0.002^{\circ} \mathrm{C}$ in temperature, 0.003 in salinity, and 3-4 dbar in pressure. The Global Positioning System was used to determine station positions.

The majority of the CTD stations were occupied at current meter mooring sites with the main purpose of using CTD profiles for temperature calibration checks of moored instruments. The limited available ship time and severe weather conditions at times allowed no additional stations between mooring sites.

The spatial distribution of the Hunter array H1-H6 of the Institut für Meereskunde Kiel is included in Fig. 3a. Mooring $\mathrm{H} 1$ was located at the western corner and $\mathrm{H} 6$ at the eastern side of the channel. H1-H3 and H6 carried current meters, H4 and H5 had near-bottom thermistor chains, bracketed by two current meters each, which unfortunately failed to record properly. An inventory of moored instruments is given in Table 1 . The array consisted of 22 Aanderaa instruments (RCM5/8), two thermistor chains (200 m long each) and an upwardlooking acoustic current profiler, which was deployed in the main thermocline. We chose a 2-h sampling rate for the recording current meters. Due to this high sampling rate the thermistor chains reached their data capacity prematurely.

Instrument placement was chosen according to the distribution of subthermocline water masses and on the basis of the available topographic information after the first site visit in 1991 (M15). Due to limited resources we had to service instruments that had been recovered from the DBE southern boundary array only a few days before redeployment (Hogg et al. 1999). This pressure of time probably led to some instrument malfunctions, restricting the overall instrument performance to about $80 \%$. More details on the processing of current meter and thermistor chain data can be found in the M28 cruise report by Zenk and Müller (1995).

We were also faced with shortcomings of the thermistor chain calibration. An individual precruise sensor calibration of the two brand-new instruments had been performed at the Institut für Meereskunde in Kiel. Both time-averaged records, representing mean temperature profiles from 11 thermistors each, displayed unrealistic deviations from a steady decrease with depths as seen in CTD profiles. Assuming a constant temperature gradient at depth, which we inferred from the initial CTD stations in the neighborhood of the mooring sites, we adjusted five of the 22 time-averaged records that had obvious offsets to these CTD stations. There may still remain a bias because no recovery or postcruise calibration check values were available. The precision of the Aanderaa instrument temperatures is estimated to be at least $\pm 0.02^{\circ} \mathrm{C}$. Despite the problems in absolute calibration the dataset (best accuracy guess $\pm 0.5^{\circ} \mathrm{C}$ ) contains valuable information on the variability of the thermal structure of the Antarctic Bottom Water flowing into the Brazil Basin.

Zenk and Hogg (1996) have reported a warming trend in the near-bottom waters of the Vema Channel. They also demonstrated a temporal tendency of two deep temperature records $(2 \mathrm{~m}$ apart in the vertical) from the Hunter Channel of order $0.5^{\circ} \mathrm{C} / 1000 \mathrm{~d}$. Since the temperature drift in the Vema Channel was corroborated by several other independent observations and since we noted the same trend in two adjacent records from the Hunter array, we assume that the sensor stability of our moored temperature recorders was sufficient. In fact, Saunders and Cherriman (1983) tested the long-term stability of comparable sensors in Aanderaa current meters with astonishingly good results $\left(<0.018^{\circ} \mathrm{C} / 1000 \mathrm{~d}\right)$.

Reliable topographic information is essential for estimating volumetric transports. The topographic data originate from surveys with the Hydrosweep system, a 

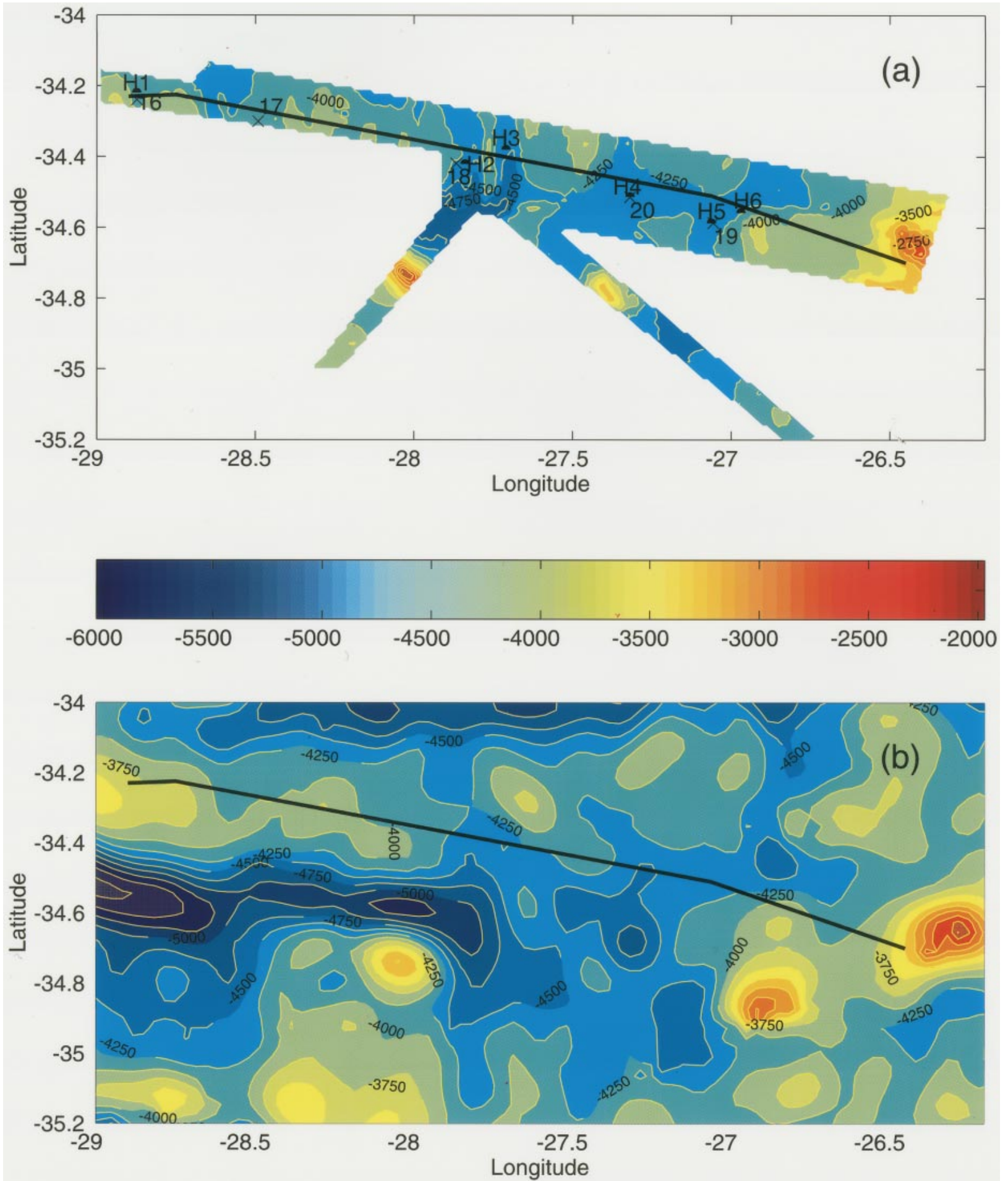

FIG. 3. Detailed topography of the Hunter Channel. Composite Hydrosweep ${ }^{\circledR}$ bathymetry (a) compiled from three Meteor cruises (M15, $22,28)$ by the bathymetric group of Alfred-Wegener-Institut, Bremerhaven. The black line represents the section shown in Fig. 4. Crosses denote M28 (May 1994) CTD profiles with associated numbers. Dots stand for current meter and thermistor chain moorings. Detailed topography of the Hunter Channel. Bathymetry inferred from satellite altimetric surveys (b) as reported by Smith and Sandwell (1997). Note that this chart was not available for guiding mooring placement. Color coding as in Fig. 3a. Depths are given in $\mathrm{m}$. 


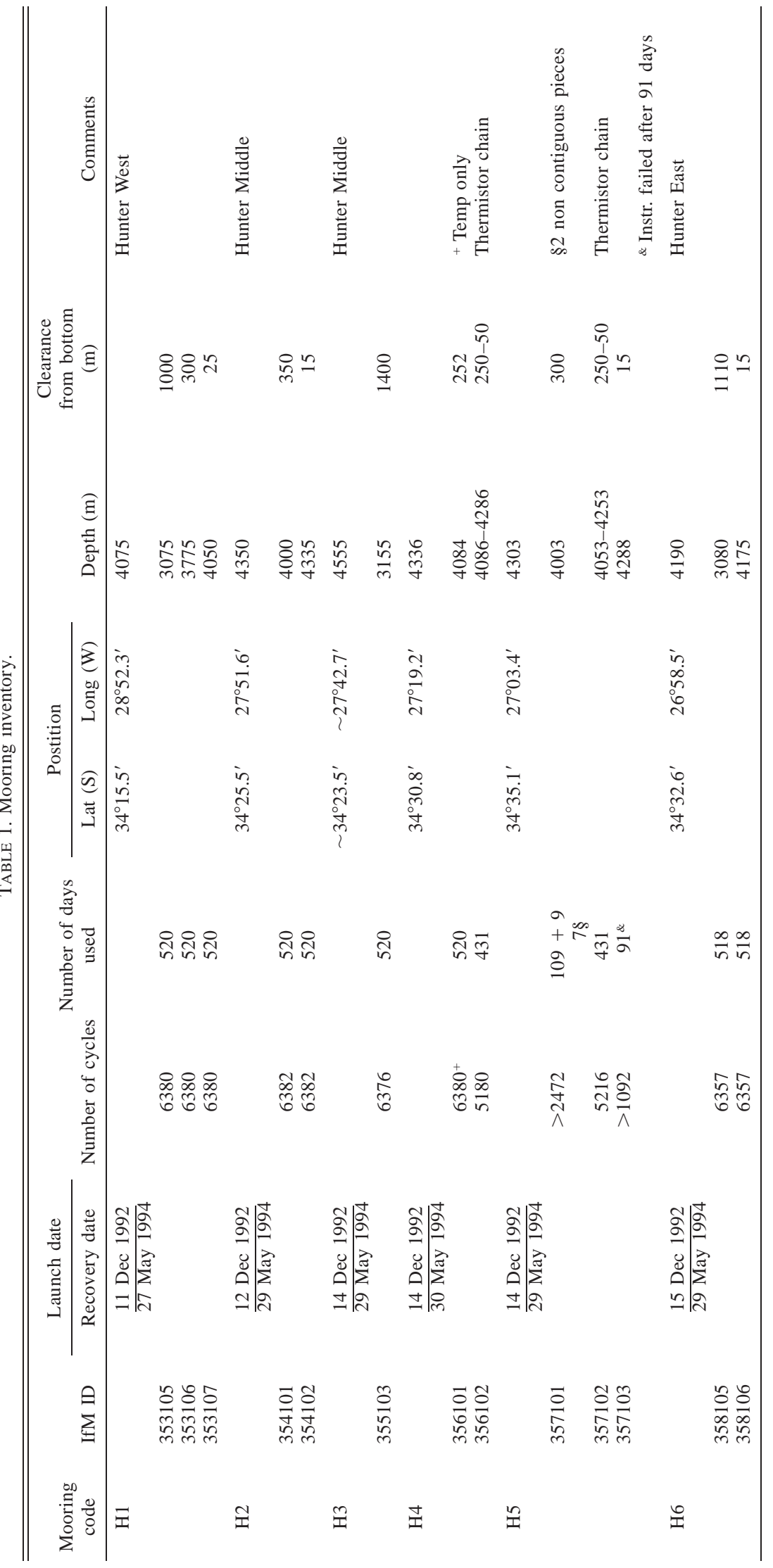



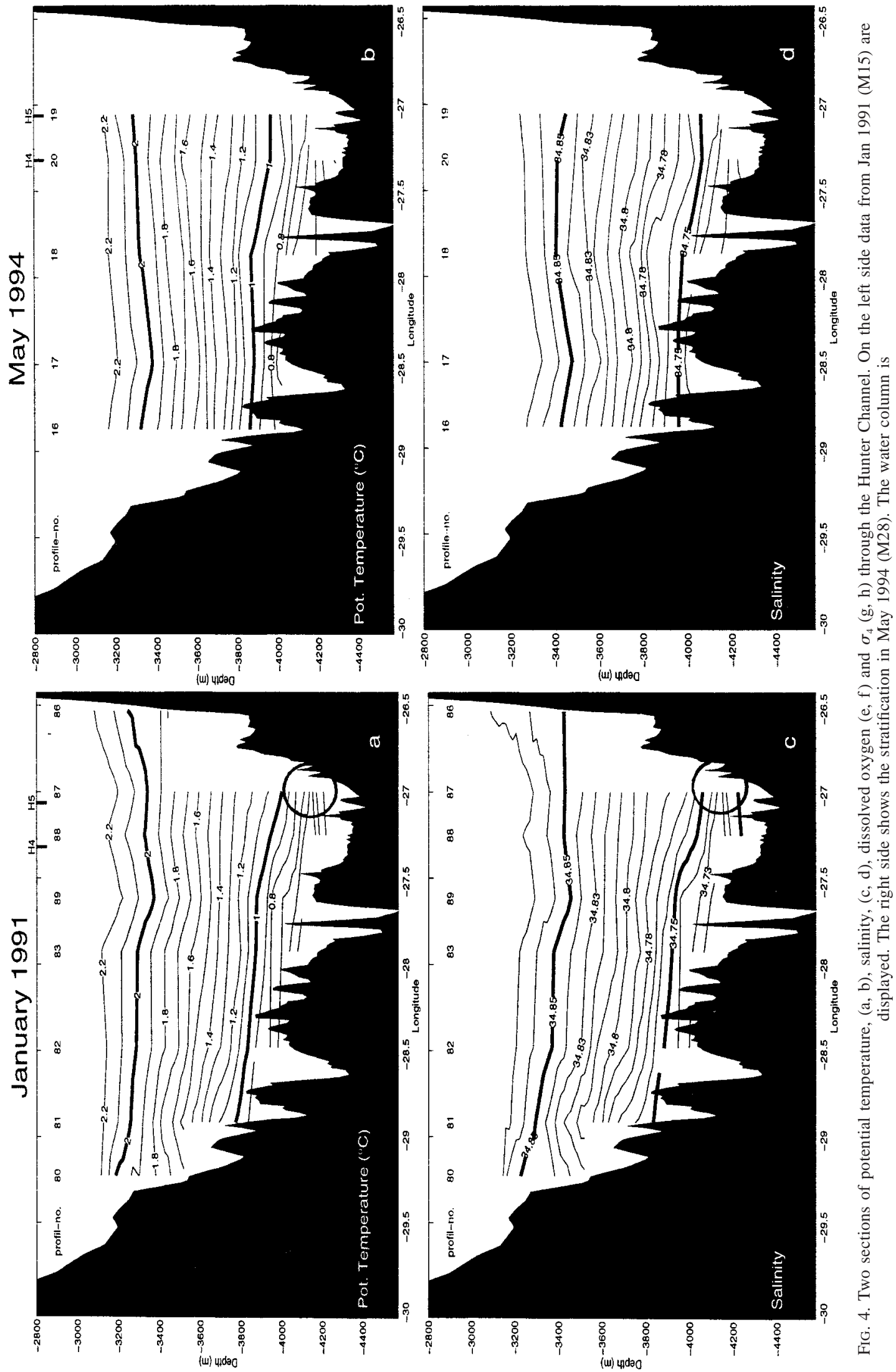

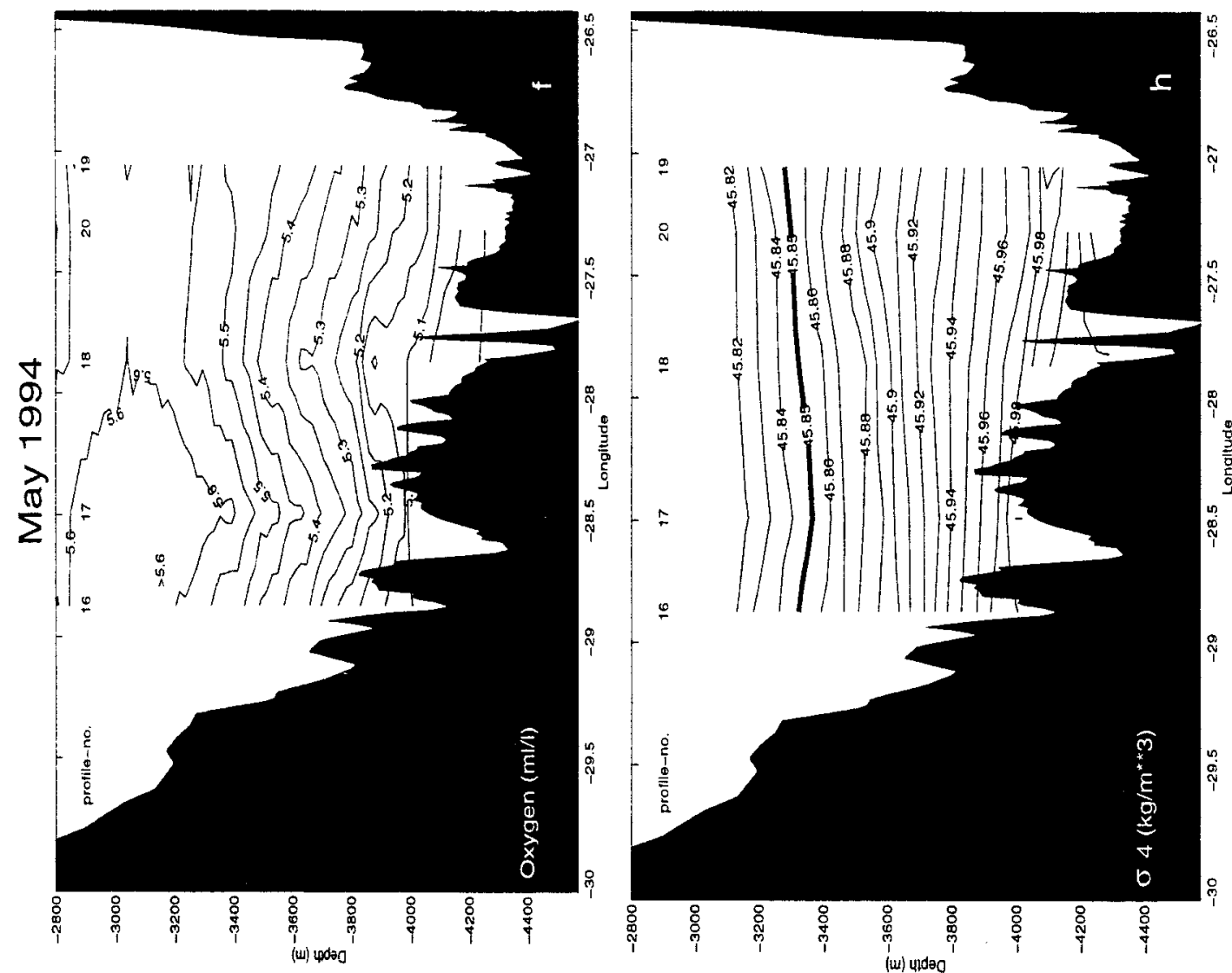

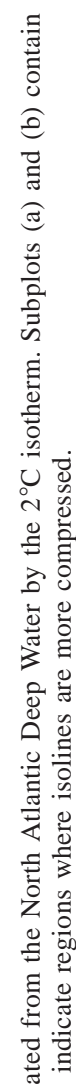
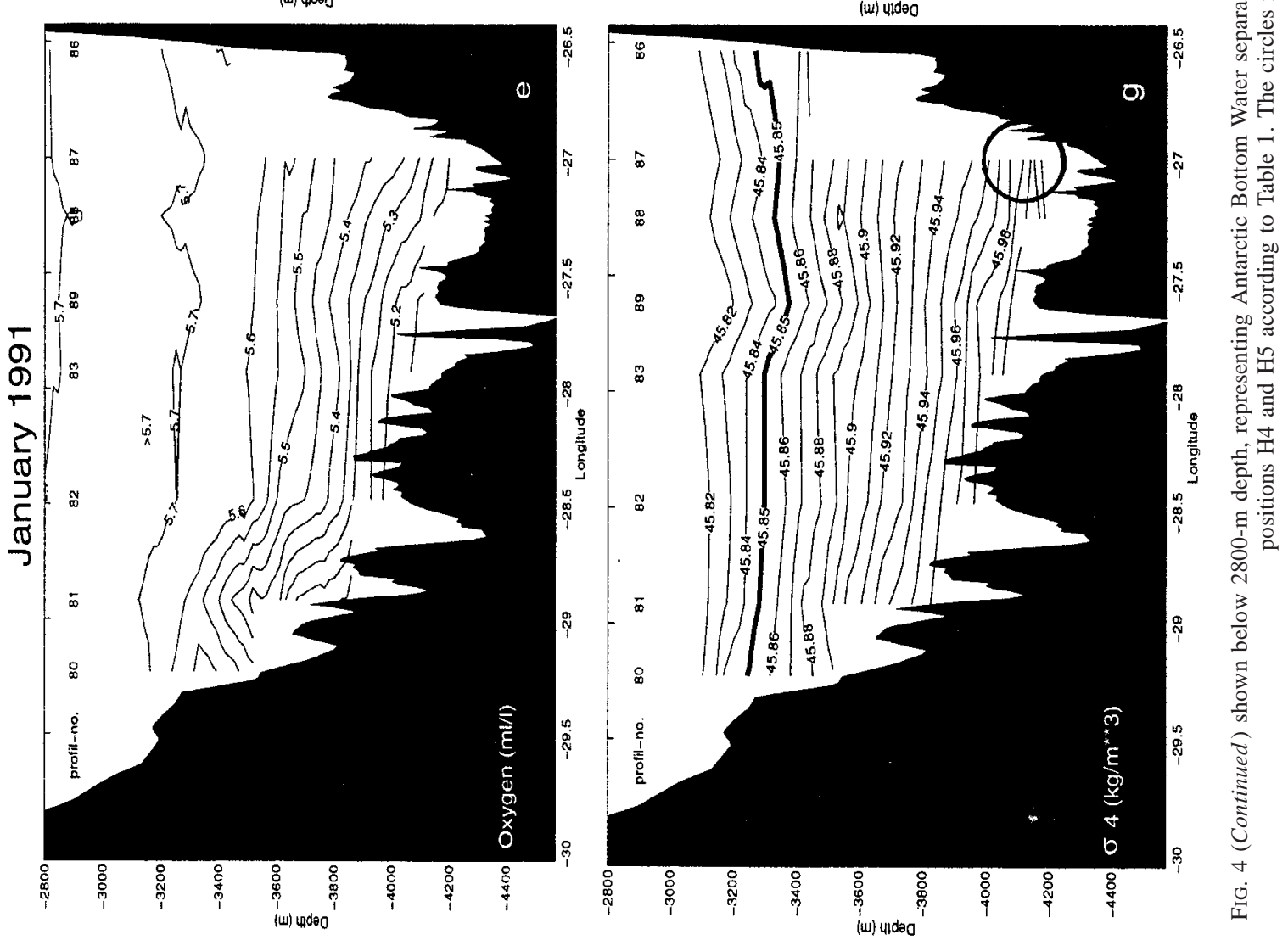
multibeam echo sounder with computer-controlled data acquisition (Pätzold et al. 1996), and were compiled by the bathymetric working group of the Alfred-WegenerInstitut in Bremerhaven. In Fig. 3a we show the resulting cross section through the Hunter Channel including mooring locations and CTD stations. We have compared our Hydrosweep chart with the ETOPO5 bathymetry provided by the National Geophysical Data Center/ NOAA (Boulder, Colorado, 80303-3328) with mediocre success. However, the more recent satellite-derived bathymetry by Smith and Sandwell (1997), which was unavailable to us during mooring deployments, shows astonishing similarities (Fig. 3b) with the directly observed Hydromap. The main sill appears to be at about $35^{\circ} 12^{\prime} \mathrm{S}, 27^{\circ} 47 \mathrm{~W}$, that is, $70 \mathrm{~km}$ upstream of our CTD sections.

Because of rough bottom topography and because of significant differences between anchor-drop location and the final mooring position, the determination of exact water depths at the mooring location can be difficult. Under unfavorable conditions, that is, next to canyon walls, the uncertainty can reach $\pm 50 \mathrm{~m}$.

\section{Temperature changes and geostrophic transports from hydrographic data}

Our first Rio Grande CTD section from January 1991 (M15) contains the densest station coverage of all our surveys in the Hunter Channel. In analyzing this dataset Speer and Zenk (1993) characterized the three main subthermocline water masses: Antarctic Intermediate Water, North Atlantic Deep Water, and Antarctic Bottom Water. Here we concentrate on the cold bottom water and its interface to the North Atlantic Deep Water. Antarctic Bottom Water (potential temperature $\theta<2.0^{\circ} \mathrm{C}$ ) in the Vema Channel can be further separated into Weddell Sea Deep Water with $\theta<0.2^{\circ} \mathrm{C}$ and Lower Circumpolar Deep Water with higher temperatures up to $2.0^{\circ} \mathrm{C}$ (Reid et al. 1977).

Zenk and Hogg (1996) and Hogg and Zenk (1997) investigated the long-term change of near-bottom temperatures in the southern Brazil Basin with emphasis on the Vema Channel. In their 24-yr-long $\theta$ time series in the Antarctic Bottom Water they found a rapid rise by $0.03^{\circ} \mathrm{C}$ from $-0.18^{\circ}$ to $-0.15^{\circ} \mathrm{C}$ in the early $1990 \mathrm{~s}$, with temperatures remaining at that level until May 1996 (Zenk et al. 1996). A more recent visit in April 1998 to the Vema sill revealed that the bottom temperatures had risen further to $-0.13^{\circ} \mathrm{C}$ (Schulz et al. 1999).

The availability of a new dataset from the Hunter Channel allows an additional check on this possibly basin-scale warming phenomenon. In Fig. 4 we display deep sections of temperature, salinity, oxygen, and density across the Hunter Channel from January 1991 (M15) to May 1994 (M28). The lowest potential temperature in 1991 ammounted to $0.225^{\circ} \mathrm{C}$. In 1994 the minimum bottom temperatures barely reached below $0.300^{\circ} \mathrm{C}$, and low salinities $<34.693$ psu observed in
1991 vanished as well, being replaced by values above 34.695 psu, but no significant change in the deep $\theta-S$ relationship was observed. The increase of near-bottom temperature and salinity values is paralleled by a slight decrease of dissolved oxygen of order $0.1 \mathrm{ml} \mathrm{l}^{-1}$. The latter seems not to be related to the lowest layer alone, but is also visible at the upper interface of Antarctic Bottom Water at the $2^{\circ} \mathrm{C}$ layer.

The Hunter Channel is about ten times wider than the Vema Channel. As in the Vema Channel, the most active overflow region of the Hunter Channel is found on its eastern side. There we find a slight pinching (circles in Figs. $4 \mathrm{a}-\mathrm{d}, \mathrm{g}, \mathrm{h})$ of isopleths, also seen in the Vema Channel, and possibly caused by a frictionally induced secondary circulation (Johnson and Sanford 1992; Jungclaus and Vanicek 1998).

In Fig. 5 we display near-bottom time series of $\theta$ and $S$ from CTD stations at H4 (Fig. 3a) within the central Hunter Channel. The curves include (stations; profiles) from M15 (92; 88), M22 (608; 48), and M28 $(318 ; 20)$. Pertinent $(\theta ; S)$ increases of $\left[\left(0.058^{\circ} \mathrm{C} ; 2.8 \times 10^{-3}\right) /\right.$ $1000 \mathrm{~d}]$ are of the same order as those reported from the Vema sill. Error bars shown in Fig. 5 represent standard deviations calculated for the lowest $20 \mathrm{~m}$ of the $\theta$ and $S$ profiles, that is, about $8-28 \mathrm{~m}$ above the ground.

Two high resolution geostrophic transport estimates of bottom-water overflow are available. Using the M15 data Speer et al. (1992) calculated a northward transport of $0.7 \times 10^{6} \mathrm{~m}^{3} \mathrm{~s}^{-1}$ of water cooler than $2^{\circ} \mathrm{C}$ through the Hunter Channel for January 1991 with an accuracy estimated to be within $\pm 50 \%$. This was based on the assumption that the velocity below the deepest common level of station pairs is representative of the whole bottom triangle set up by these stations. Speer et al. (1992) conjectured that a higher horizontal station resolution, revealing some bottom intensified flow, would raise the transport closer to $1 \times 10^{6} \mathrm{~m}^{3} \mathrm{~s}^{-1}$. Northward bottom velocities were of order $1 \mathrm{~cm} \mathrm{~s}^{-1}$ (Fig. 6a, recalculated as follows). A rather limited countercurrent of about $-0.5 \mathrm{~cm} \mathrm{~s}^{-1}$ was present at $27^{\circ} 30^{\prime} \mathrm{W}$.

The second Hunter Channel geostrophic shear section (Fig. 6b) was obtained three years later during M28 in May 1994. As in Fig. 6a, the $2^{\circ} \mathrm{C}$ isotherm was chosen as an upper limit of bottom water. For the bottom triangles we assumed a linear decrease of the current at the lowest data pair to zero over a distance of $1000 \mathrm{~m}$. The resulting geostrophic current distribution (Fig. 6b) appears to be dominated by an eddy structure with rotational speeds exceeding $0.5 \mathrm{~cm} \mathrm{~s}^{-1}$ in its core. To our surprise, the bottom-water export to the Brazil Basin had almost ceased $\left(<0.1 \times 10^{6} \mathrm{~m}^{3} \mathrm{~s}^{-1}\right)$.

Similar to Speer et al. (1992) we tested the sensitivity of transports with respect to the choice of the level of no motion selected between the North Atlantic Deep Water and Antarctic Bottom Water. Virtually no difference could be detected between the cases $\theta=2^{\circ} \mathrm{C}$ and $\sigma_{4}=45.85 \mathrm{~kg} \mathrm{~m}^{-3}$ both producing $0.77 \times 10^{6} \mathrm{~m}^{3} \mathrm{~s}^{-1}$ with M15 recalculated using the bottom triangle method 
described above. The $\sigma_{4}$-option was preferred by Zemba (1991) on her section across the lower Santos Plateau and the Vema Channel, not including the Hunter Channel. Only minor deviations $\left( \pm 0.06 \times 10^{6} \mathrm{~m}^{3} \mathrm{~s}^{-1}\right)$ are found when varying the reference potential temperature from $1.9^{\circ}$ to $2.1^{\circ} \mathrm{C}$.

The results from our two CTD sections (M15 and M28) across the Hunter Channel suggest that the channel is a potential additional conduit for highly variable bottom water transports across the southern boundary of the Brazil basin. As we shall establish with the time series data from the moored instruments, the large difference found between the two sections is not atypical. These results emphasize the general problem of the representativeness of synoptic measurements in regions with strongly varying properties which can be clarified by long-term moored instrumentation (Rudnick 1997; Hogg et al. 1999).

\section{Temperature changes from moored instruments}

Thermistor chain records are available from locations H4 (depth $4336 \mathrm{~m}$ ) and H5 (4303 m), which are given in Figs. 4a and 4b. Their separation amounts to approximately $26 \mathrm{~km}$, that is, they cover $13 \%$ of the total width of the Hunter Channel. In Fig. 7 we display the daily averaged time series of temperature at these positions. Short-term temperature fluctuations exceeding $0.2^{\circ} \mathrm{C}$ in magnitude are superimposed on a long-term trend as, for example, around day 215 in both records in Fig. 7. Fitting straight lines in a least square sense to the curves provides temperature trends and standard errors at different heights off the bottom (Fig. 8). The largest values $\left(>0.5^{\circ} \mathrm{C} / 1000 \mathrm{~d}\right)$ are found in the upper portion of the water column at $\mathrm{H} 4$. Their magnitudes are confirmed by the independent current meter thermistor (IfM Ref. 356101 in Table 1, shown by the star in Fig. 8), $2 \mathrm{~m}$ above the uppermost thermistor of the $\mathrm{H} 4$ chain. The $\mathrm{H} 5$ chain delivered more uniform values between 0.2 and $0.3^{\circ} \mathrm{C} / 1000 \mathrm{~d}$. This general long-term warming signal resembles observations from moored instruments found at the equator by Hall et al. (1997).

Assuming a simple geostrophic balance in the trough between $\mathrm{H} 4$ and H5 (Fig. 3a), we expect slope changes of the thermal stratification to be proportional to local changes of bottom-water throughflow. In Fig. 9 we display fluctuations of the distance of the $0.9^{\circ} \mathrm{C}$ isotherm from the bottom as inferred from $\mathrm{H} 4$ and $\mathrm{H} 5$ with slight extrapolations below 50 and above $250 \mathrm{~m}$. The $0.9^{\circ} \mathrm{C}$ isotherm was the only isotherm common to $\mathrm{H} 4$ and $\mathrm{H} 5$. We note that during the first 130 days the extrema of the low-passed time series are out of phase. Around day 100 the $0.9^{\circ} \mathrm{C}$ isotherm reaches its maximum elevation $(250 \mathrm{~m})$ above the bottom on the western side $(\mathrm{H} 4)$ while almost simultaneously it approaches a minimum of $65 \mathrm{~m}$ in the east (H5). Beyond day 320 there is a thinning of the $<0.9^{\circ} \mathrm{C}$ layer in the west with little net change in the east. Geostrophically speaking the first
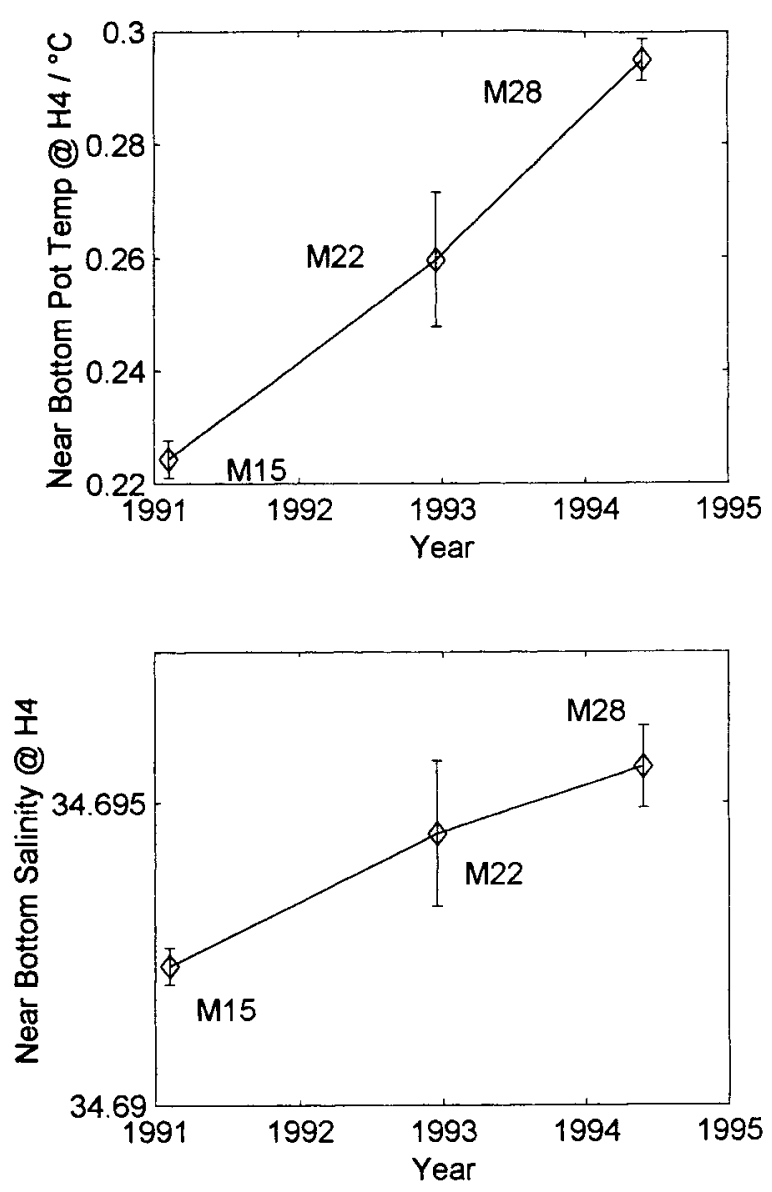

FIG. 5. Near-bottom time series of potential temperature (a) and salinity (b) at location H4. Data were selected in the deepest observed level approximately 8-28 m above the bottom. Error bars give standard deviations within this near-bottom layer. The implied temperature slope amounts to $0.055^{\circ} \mathrm{C} / 1000 \mathrm{~d}$.

period corresponds to a strong bottom-water export situation and the second to slower flow.

\section{Transport of Antarctic Bottom Water}

Now we turn to direct measures of the Hunter Channel throughflow. Before estimating spatial integrals of the cross-sectional flow, we select time series from Table 1 whose near-bottom, daily averaged, current meter records display a persistent equatorward flow (Fig. 10). Current reversals exist in all records, with time scales of 1-2 weeks.

Highest speeds were observed on the eastern side of the Hunter Channel (H6), $15 \mathrm{~m}$ above the bottom. Both current components had typical values above $4 \mathrm{~cm} \mathrm{~s}^{-1}$, resulting in an average speed of $7.1 \mathrm{~cm} \mathrm{~s}^{-1} \pm 3.2 \mathrm{~cm}$ $\mathrm{s}^{-1}$ and a maximum speed of $17.6 \mathrm{~cm} \mathrm{~s}^{-1}$. The large eastward flow at this site is caused by the local orientation of a deep northeast-oriented valley (cf. Fig. 3). Mean meridional components of about $0.9 \mathrm{~cm} \mathrm{~s}^{-1}$ are characteristic for the central and western sides of the 

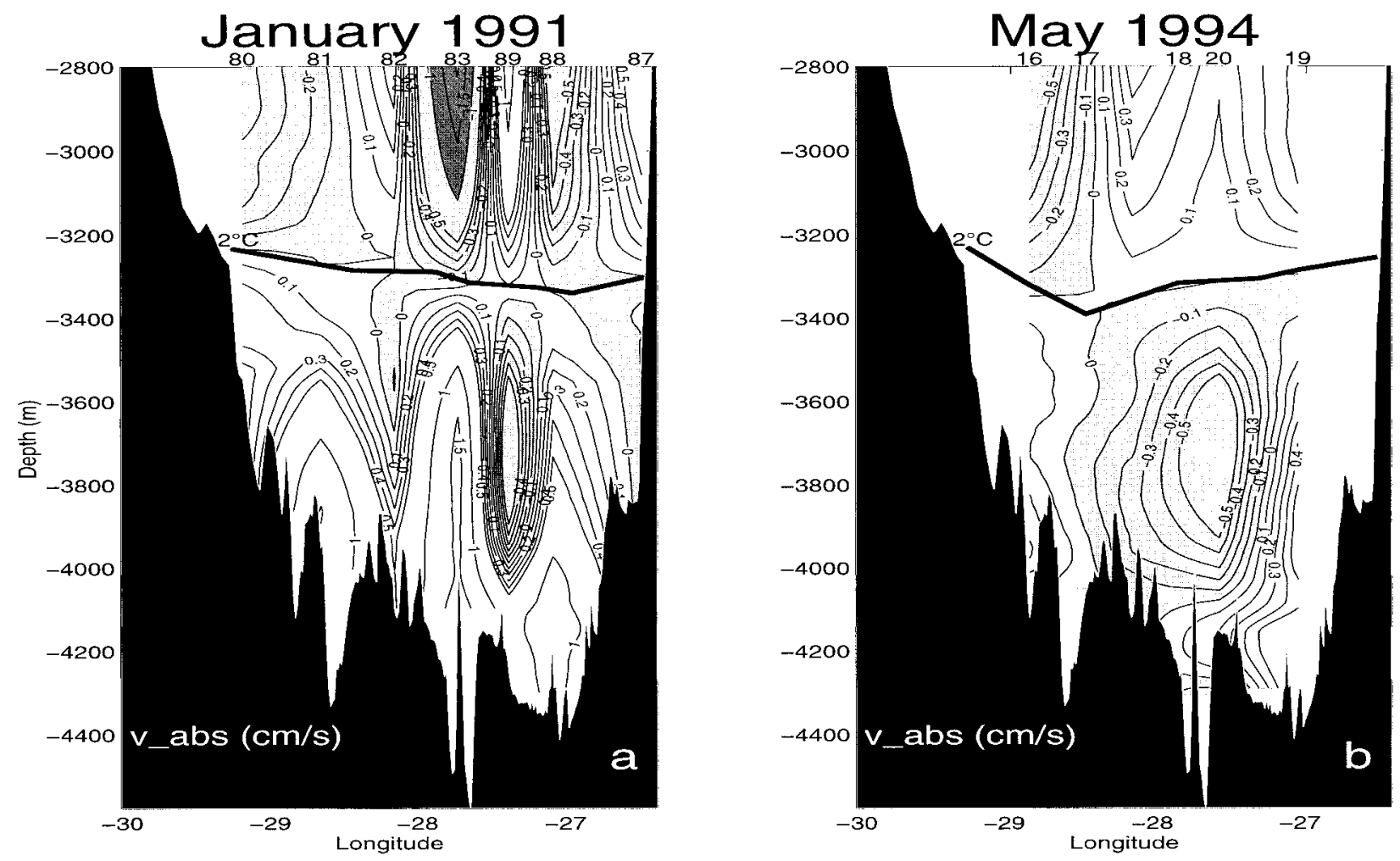

FIG. 6. Geostrophic current $\left(\mathrm{cm} \mathrm{s}^{-1}\right)$ distribution relative to the depth of the $2^{\circ} \mathrm{C}$ isotherm in Figs. 4a,b. Note the fundamental difference in the distributions from (a) Jan 1991 and (b) May 1994. The general import of bottom water into the Brazil Basin (see Fig. 1) was heavily disturbed by the midchannel returnflow between profiles 17 and 19 in (b).

Hunter Channel. Cumulative averages of meridional current components (Fig. 10) indicate that a stable estimate of the northward component is obtained after 200 or more days.

Short term flow reversals are significantly anticorrelated (correlation coefficient -0.62 for unfiltered daily data) with temperature fluctuations of Antarctic Bottom Water. In Fig. 11 we present an example, showing current extrema out of phase by $180^{\circ}$ with temperature anomalies and indicating a southward eddy advection of heat which adds to that by the mean as is generally true as well in the Vema Channel region (Hogg et al. 1998).

To estimate daily averaged transports through the Hunter Channel we need to make a number of assumptions. Because of the scarcity of long-term time series we used only three partitions for the whole Hunter Channel zone (cf. Fig. 10a). Each subdivision, West (W), Middle (M), and East (E), extends in the vertical from the bottom to the $2^{\circ} \mathrm{C}$ isotherm as observed during M15. This upper boundary is generally accepted as the upper limit of the Antarctic Bottom Water in this region (Broecker et al. 1976; Speer and Zenk 1993). Because of their short distance (7 km apart) we consider $\mathrm{H} 2$ and H3 (where the deepest instrument failed) as a quasisingle mooring. Segments $\mathrm{W}$ and $\mathrm{M}$ in Fig. 10a are separated by the center line between moorings $\mathrm{H} 1$ and $\mathrm{H} 2 / \mathrm{H} 3$ at $28^{\circ} 20^{\prime} \mathrm{W}$.

The dividing line between $\mathrm{H} 2 / \mathrm{H} 3$ and the easternmost mooring $\mathrm{H} 6$ was shifted eastward towards H5. The current meter on this mooring yielded only a three-month long observations and was thus insufficient to meet the stability criterion of the mean of about $200 \mathrm{~d}$ (right side of Fig. 10). Nonetheless, a comparison of these fragmentary data with those from the central Hunter Channel (H2) shows a notable degree of horizontal coherence, which we do not find in the pair H2, H6. While the initial southward flow at $\mathrm{H} 2$ is well reproduced at $\mathrm{H} 5$, no such month-long reversals were ever seen at $\mathrm{H} 6$ with its almost persistent northeastward flow (Fig. 10h). The apparent difference in the flow characteristics between the middle part of the channel and its eastern slope region led us to set the partition at $27^{\circ} \mathrm{W}$ (Fig. 10a).

Further assumptions had to be made with respect to the effective cross section and the representative vertical current profiles for the subdivisions. No Hydrosweep data were available from the westernmost part of the Hunter Channel. Instead we used the regular echo sounder profile from the first visit of the Meteor (M15) to complete the total cross section below the $2^{\circ} \mathrm{C}$ isotherm at $3200 \mathrm{~m}$. 

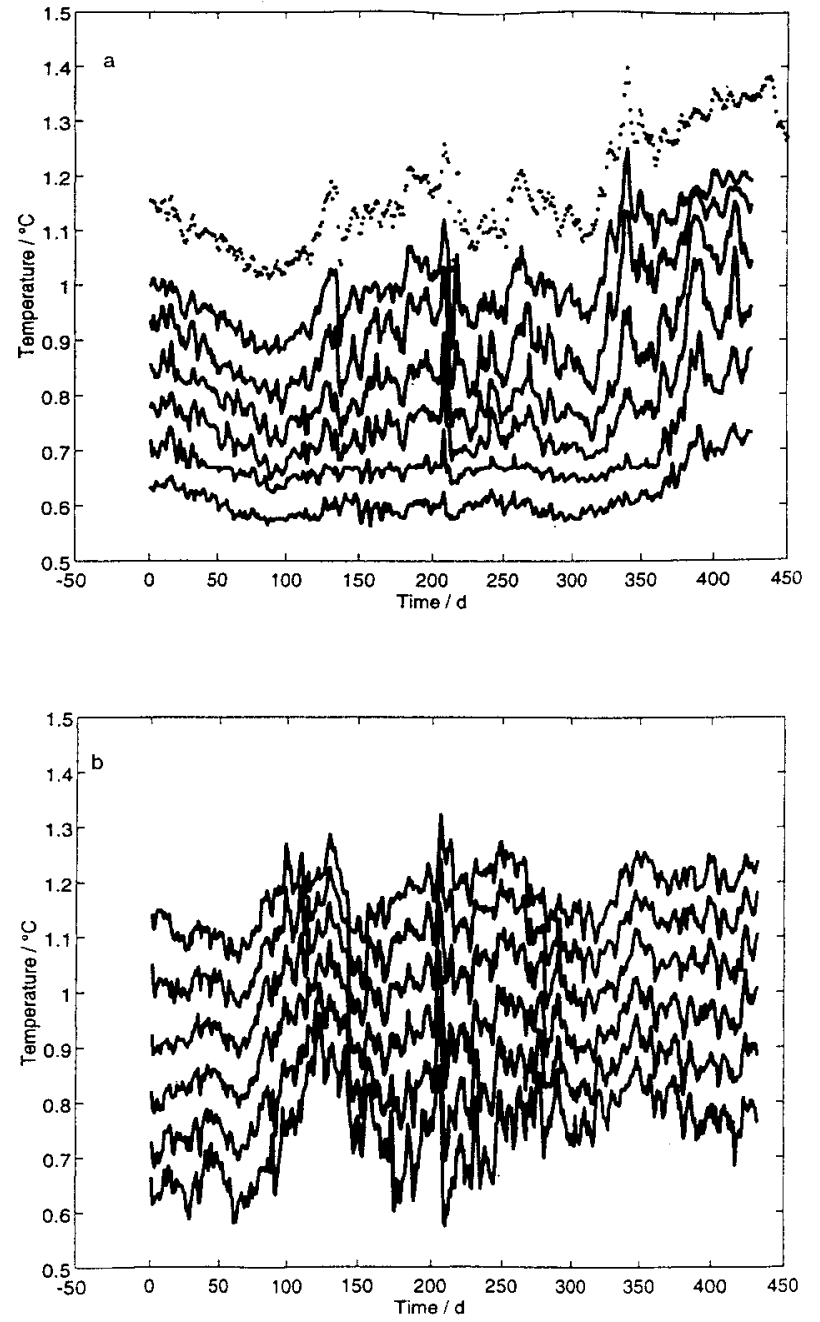

FIG. 7. Time series of potential temperature of Antarctic Bottom Water recorded by thermistor chains $\mathrm{H} 4$ (a) and $\mathrm{H} 5$ (b). For positions see Fig. 3a and Table 1. Both chains yielded records from 11 sensors of which every other record is displayed here. Two meters above the uppermost thermometer of $\mathrm{H} 4$ was an independent self-contained current meter (356101 in Table 1) with temperature sensor. Its record (dotted) was shifted upward by $0.2^{\circ} \mathrm{C}$. For accuracies and stability see text. Note the substantial fluctuations which occasionally exceeded $0.2^{\circ} \mathrm{C}$ in amplitude.

We constructed daily vertical profiles, which were then digitized to $5-\mathrm{m}$ thick layers per subdivision. In case of $\mathrm{W}$ and $\mathrm{M}$ these profiles were obtained by linear interpolation between the current meters and an assumed value of zero at the sea floor. For transport calculations speed profiles were then weighted by the actual cross sections of the subdivisions. Time-averaged profiles from subdivisions $\mathrm{W}$ and $\mathrm{M}$ are shown in Figs. 12a,b.

The generation of the third profile (Fig. 12c) from H6 at the eastern side (H6) was more difficult because the most important current meter in the core layer of Antarctic Bottom Water had failed. Encouraged by similar flow properties at other conduits for bottom water in the Atlantic, we solved the problem by introducing a sim-

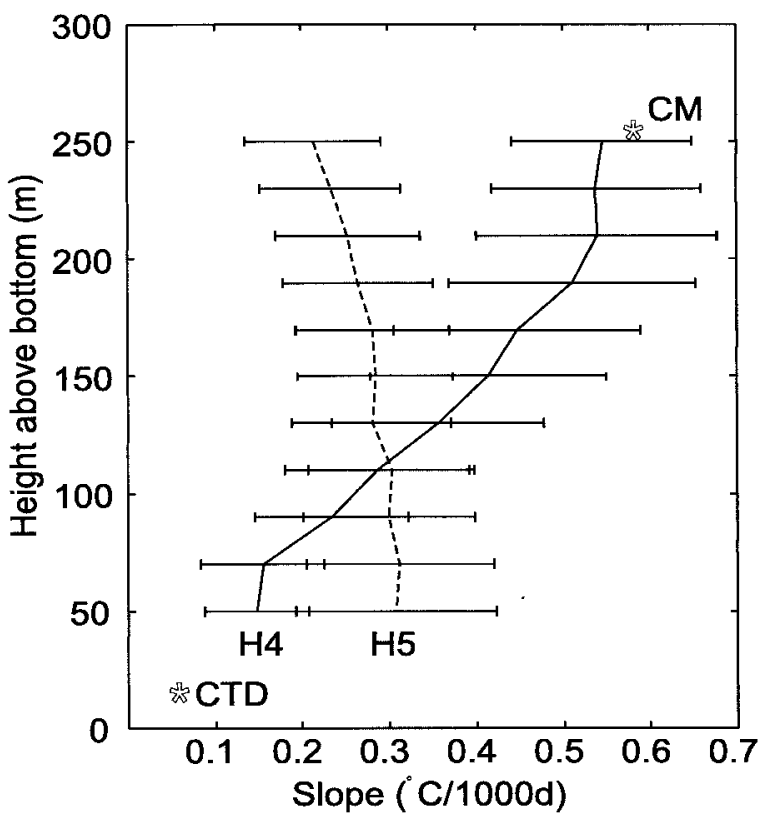

FIG. 8. Vertical profiles of temperature slopes of thermistor chains at $\mathrm{H} 4$ and H5. Pertinent time series are shown in Fig. 7. The uppermost data point at $\mathrm{H} 4$ belongs to the current meter (346101 in Table 1) temperature record shown on top of Fig. 7a. The lowest point represents the temperature increase observed by the three CTD casts at H4 shown in Fig. 5a.

ilarity argument. In doing so, we assumed that the overflows in these conduits are all governed by the same physical processes (Whitehead 1998). In Fig. 12d we show mean profiles from three other abyssal flow regimes in deep passages: the Vema Channel (see Fig. 1) farther to the west (Hogg et al. 1998), the equatorial Romanche Fracture Zone (Mercier and Speer 1998), and the Vema Fracture Zone at $11^{\circ} \mathrm{N}$ (Vangriesheim 1980).

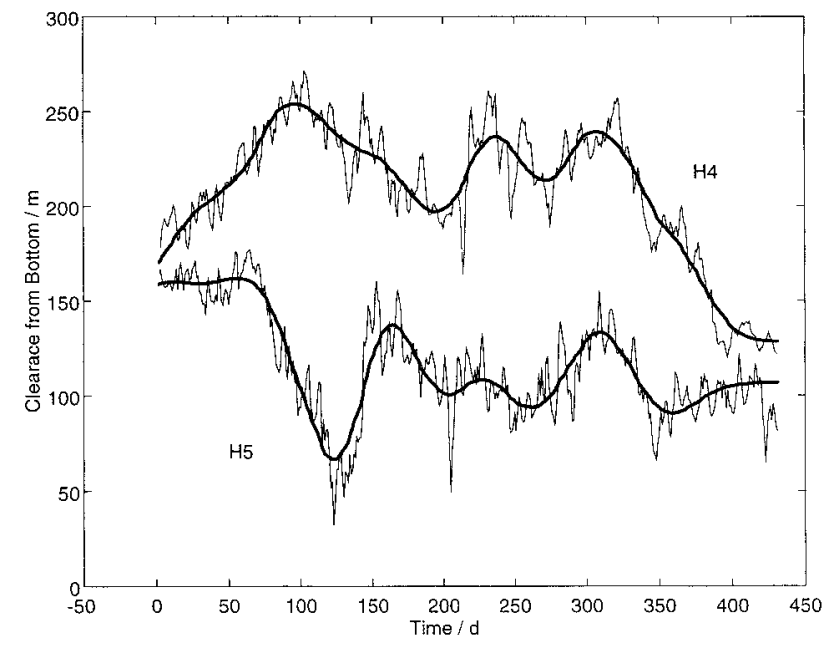

FIG. 9. Local variations of the $0.9^{\circ} \mathrm{C}$ isotherm at $\mathrm{H} 4$ (top curves) and $\mathrm{H} 5$ (bottom curves) as computed from daily averaged data shown in Fig. 7. Data low-passed at 80 days are superimposed. For geographical details see Fig. 3 . 

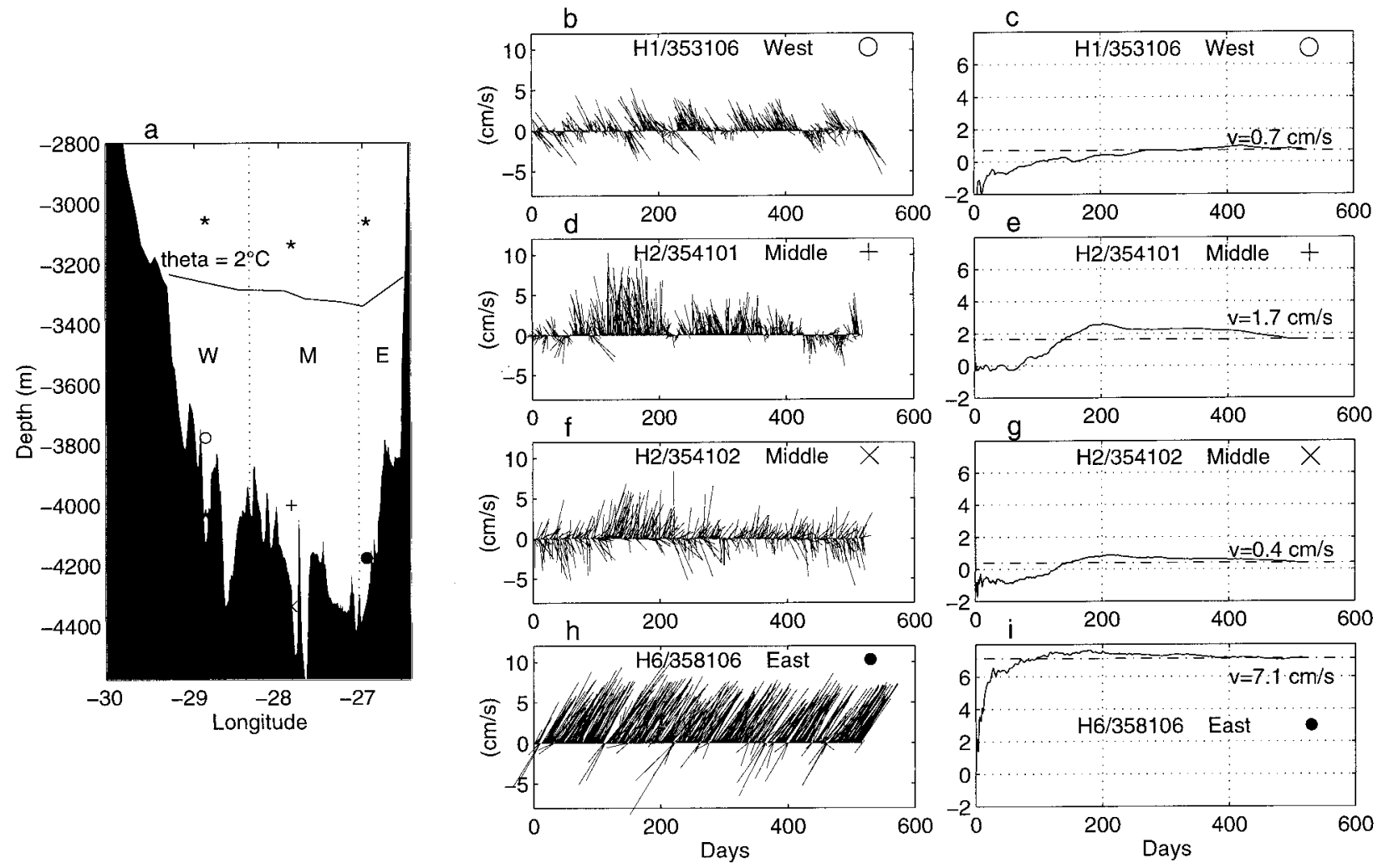

FIG. 10. Locations (a) of current meter positions (cf. Table 1) and divisions West (W), Middle (M), and East (E) in the Hunter Channel, current vector plots (north component upward) as time series $(\mathrm{b}, \mathrm{d}, \mathrm{f}, \mathrm{h}$ ), and diagrams of the cumulative means of the meridional current components (c, e, g, i). Note the control character of the local topography and the minimum time of approximately 200 days for obtaining a stable mean.

For normalizing the $z$ axis we used the distances between the current meters nearest to the bottom (15-50 $\mathrm{m}$ above the ground) and a common depth where speeds had decreased to $14 \%$ of their maximum $\left(z_{14}\right)$. Average

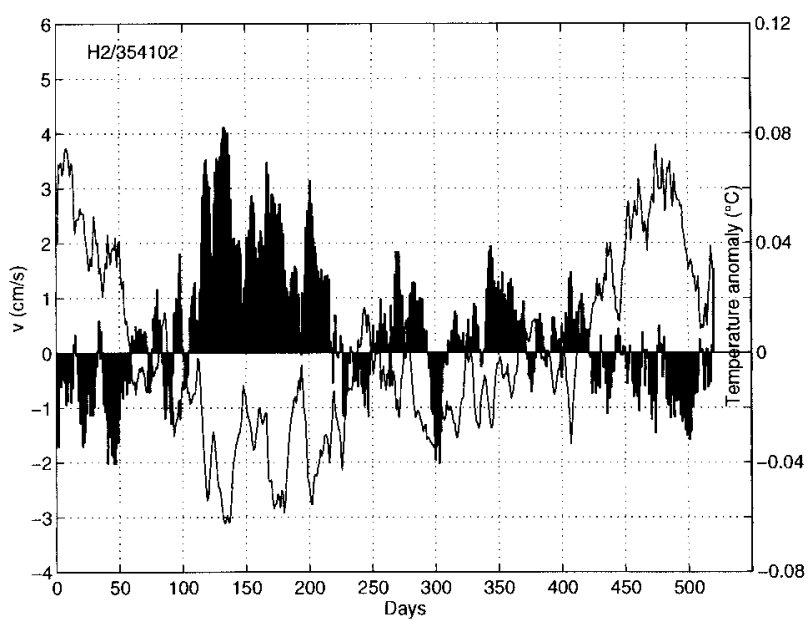

FIG. 11. Representation of the high coherence between northward advection (filled curve) and temperature fluctuations (line). Negative temperature anomalies are coupled with increased throughflow at $\mathrm{H} 2$. Data were recorded by current meter 354102 (cf. Table 1). velocity maxima served as scaling factors on the abscissa. By calculating an averaged profile for the three samples and by utilizing the daily $15 \mathrm{~m}$ above the bottom records of $\mathrm{H} 6$ we were able to infer a time series of current profiles for H6. Its mean is shown in Fig. $12 \mathrm{c}$.

In Fig. 13a we present the Hunter Channel transport time series with daily resolution, consisting of the sum of $\mathrm{W}, \mathrm{M}$, and $\mathrm{E}$ contributions. Figure 13b depicts the cumulative mean, referenced to the deployment date of the instruments. The frequency distribution of the total transport is given in Fig. 13c. After the earlier discussion on the necessary minimum length of averaging for obtaining the mean current, it is not surprising to find a corresponding timescale in the cumulative transports (Fig. 13b). The mean and the standard deviation amount to $2.92( \pm 2.56) \times 10^{6} \mathrm{~m}^{3} \mathrm{~s}^{-1}$. The maximum transport occurred in June 1993, exceeding $+11 \times 10^{6} \mathrm{~m}^{3} \mathrm{~s}^{-1}$. Its impact on the mean was compensated only 6 weeks later by the minimum transport of $-5 \times 10^{6} \mathrm{~m}^{3} \mathrm{~s}^{-1}$ during a current reversal event of only a few days duration.

In Fig. 13a we have overlaid a low-pass filtered (cutoff period $150 \mathrm{~d}$ ) transport curve: there are maxima in May and October hinting at a semiannual transport var- 

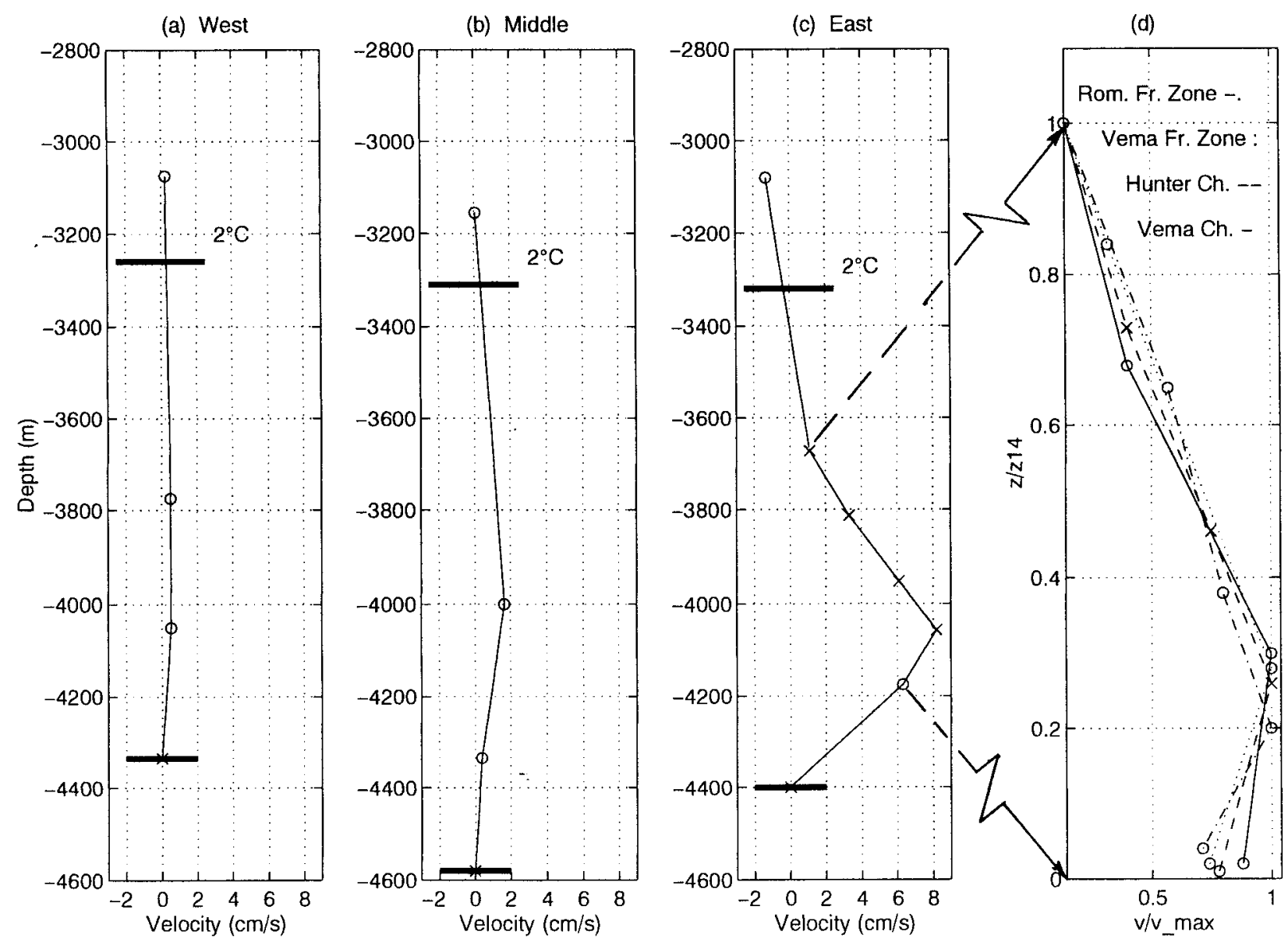

FIG. 12. Averaged vertical current profiles of the recorded meridional current components at subdivisions West (a), Middle (b), and East (c) according to Fig. 10a. Curve East (c) was inferred by a similarity argument involving comparable records from Vema Channel, Vema Fracture Zone, and Romanche Fracture Zone. For details see text. In all cases the transport integration extended between the $2^{\circ} \mathrm{C}$ potential temperature isotherm (see Fig. 4a) and the bottom. (The averaged current profile from the Romanche Fracture Zone was kindly provided by H. Mercier before publication.)

iation. A closer look shows that this signal originates mainly from the middle division of the channel. Strong semiannual transport fluctuations of bottom water were also reported by Mercier and Speer (1998) and Hall et al. (1997) from their near-equator bottom-water channels.

The alternating northward and southward flow in December 1992 is compatible with the near-zero geostrophic transport estimate from the current meter deployment cruise (M28). The histogram of flux variability (Fig. 13c) is similar to that obtained by Holfort (1994) for the Vema Channel. He obtained a variability range between 0.5 and $17\left(\times 10^{6} \mathrm{~m}^{3} \mathrm{~s}^{-1}\right)$ in a 23 -month long current meter record. His calculated mean transport of $6.4( \pm 3.0) \times 10^{6} \mathrm{~m}^{3} \mathrm{~s}^{-1}$ below the $2^{\circ} \mathrm{C}$ isotherm confirmed that the Vema Channel remains the main exchange region for bottom water at the Rio Grande Rise.

The mean transport of Circumpolar Deep Water in the Hunter Channel was allocated to potential temperatures in $0.2 \mathrm{~K}$ classes (Fig. 14a). We recognize an overflow peak at $1.1^{\circ} \mathrm{C}$, which is dominated by the eastern outlet (not shown). For reasons of compatibility with similar calculations in the literature we have added transports split into density anomaly $\left(\sigma_{4}\right)$ classes (Fig. 14b). The Hunter Channel transport-weighted temperature is $1.19^{\circ} \mathrm{C}$, about $0.2^{\circ}$ and $0.3^{\circ} \mathrm{C}$ below comparable values reported for the Romanche and Chain Fracture Zones, respectively (Mercier and Speer 1998).

In their comparable analysis from the deep equatorial passages Mercier and Speer discuss a number of error sources, equally relevant here: interpolations of velocities between instruments, extrapolations at margins, and the choice of cross sections. Measurement errors due to mechanical sensors are thought to be small compared to sampling errors. They concluded that their sampling error was about $10 \%-15 \%$. Another exemplary error analysis of bottom-water transports can be found in Rudnick's (1997) study of the Samoa Passage throughflow. He used an objective analysis scheme based on a much more complete database. 
(a) Daily and Filtered Transports

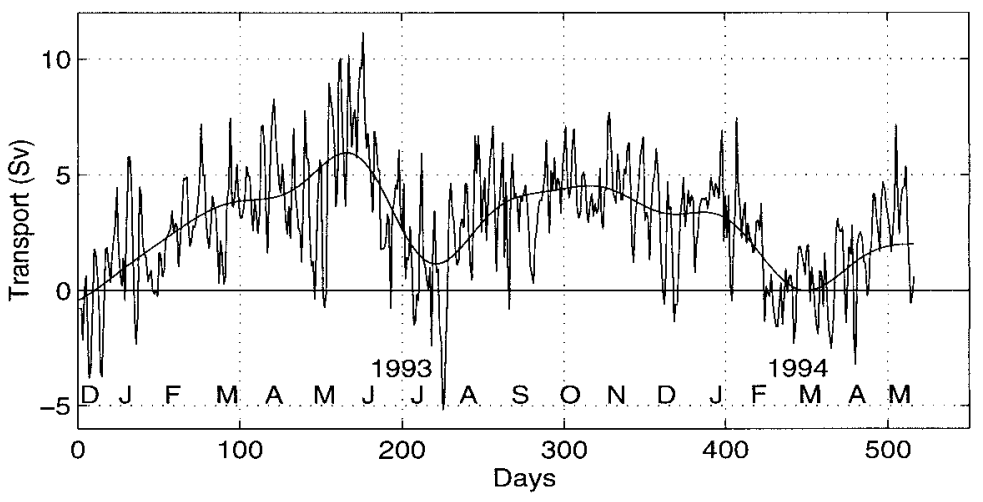

(b) Cumulative Means

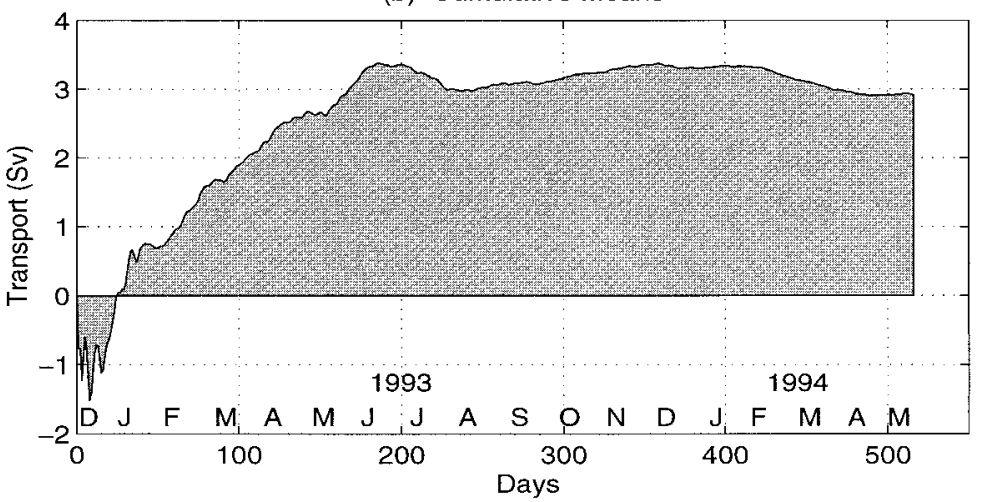

(c) Frequency Distribution

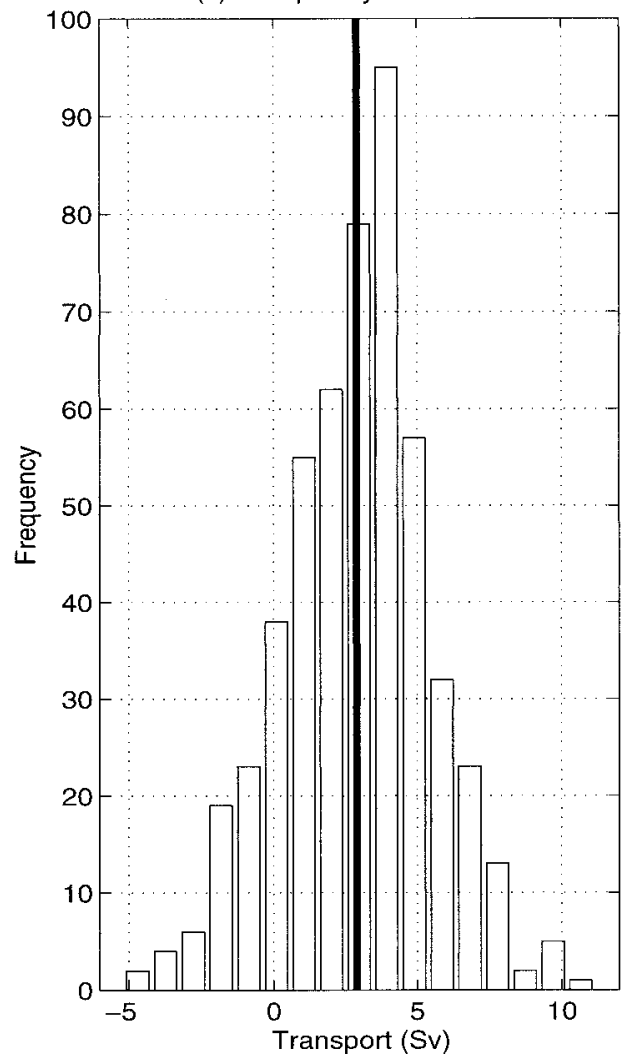

FIG. 13. The transport time series of Antarctic Bottom Water (a) through Hunter Channel and the cumulative mean (b) approaching 2.9 $\times 10^{6} \mathrm{~m}^{3} \mathrm{~s}^{-1}$ after approximately 200 days. Frequency distribution (c) in days with a thick line representing the mean $\left(\mathrm{Sv} \equiv 10^{6} \mathrm{~m}^{3} \mathrm{~s}^{-1}\right)$. In subplot (a) we overlaid a low-passed filtered curve to show a possible semiannual periodicity.

We have also performed a series of test calculations to estimate the accuracy of our Hunter transports.

1) We varied the position of the upper boundary of Antarctic Bottom Water by $\pm 90 \mathrm{~m}$, a value compatible with the displacement of the $0.9^{\circ} \mathrm{C}$ isotherm in segment $\mathrm{M}$. Total transport variations were of order $\pm 0.10 \times 10^{6} \mathrm{~m}^{3} \mathrm{~s}^{-1}$.

2) Ambiguities in the spatial extrapolation scheme were estimated as $\pm 20 \mathrm{~km}^{2}$, resulting in transport variations of $\pm 0.30 \times 10^{6} \mathrm{~m}^{3} \mathrm{~s}^{-1}$.

3) We tried a logarithmic boundary layer profile below the deepest current meters and the floor instead of a linear decrease. The effect was small: $0.10 \times 10^{6}$ $\mathrm{m}^{3} \mathrm{~s}^{-1}$.

4) In the case of subdivision $E$ we varied the upper zero-crossing of the inferred "universal" current profile by $\pm 100 \mathrm{~m}$. The resulting changes in the total transport were less than $10 \%\left( \pm 0.23 \times 10^{6} \mathrm{~m}^{3} \mathrm{~s}^{-1}\right)$.

5) We have calculated a standard error for the obtained mean transport of Antarctic Bottom Water through the Hunter Channel below $\theta=2^{\circ} \mathrm{C}$. Assuming a Gaussian distribution of the daily transport values (cf. Fig. 13c) we can approximate the essential degrees of freedom or number $N$ of independent ob- servations by the ratio of the record length $T$ to twice the integral timescale $\tau$. The latter was estimated from the integral of the normalized autocorrelation function (biased estimate, see Bendat and Piersol 1966) of the transport time series from the origin to the first zero crossing: $N=T / v=516 \mathrm{~d} / 22.5 \mathrm{~d} \approx$ 23 . Further, the $95 \%$ confidence interval, $E_{T}$, due to the finite length of the time series can be calculated from the standard deviation, $s$ :

$$
\begin{aligned}
E_{T} & =s \frac{2.2}{\sqrt{N}}=2.56 \times 10^{6} \frac{2.2}{\sqrt{23}} \mathrm{~m}^{3} \mathrm{~s}^{-1} \\
& =1.17 \times 10^{6} \mathrm{~m}^{3} \mathrm{~s}^{-1}
\end{aligned}
$$

where the numerator comes from the Student ttest with 22 degrees of freedom (Table 4.9 in Bendat and Piersol 1966).

6) If we assume the known spatial uncertainties (a)-(d) to be independent, we can estimate their total rms impact: $E_{s}=0.4 \times 10^{6} \mathrm{~m}^{3} \mathrm{~s}^{-1}$. This error due to the limited spatial resolution of the Hunter Channel exceeds the $0.3 \times 10^{6} \mathrm{~m}^{3} \mathrm{~s}^{-1}$ for the Samoan Passage, which is of approximately equal width (Rudnick 1997). The value for $E_{s}$ probably still under- 

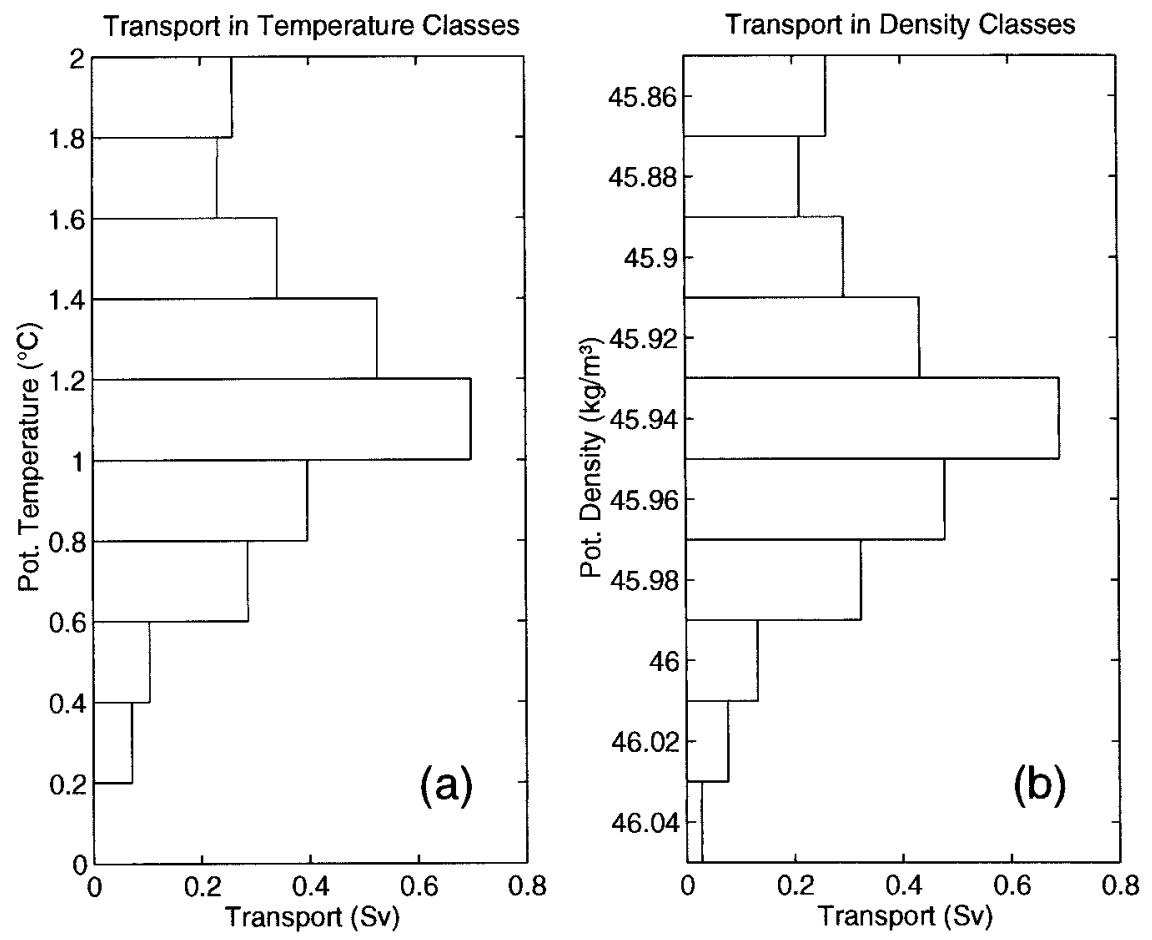

FIG. 14. Total transports of Antarctic Bottom Water through Hunter Channel split into potential temperature (a) and $\sigma_{4}$ density classes (b). The shown classes were inferred from CTD profiles in Fig. 2.

estimates the error caused by the failure of the second deepest current meter in subdivision E.

7) A lower bound estimate for the total rms error yields $E_{\Sigma}=\sqrt{E_{T}^{2}+E_{S}^{2}}=1.24 \times 10^{6} \mathrm{~m}^{3} \mathrm{~s}^{-1}$ associated with the mean transport of $2.92 \times 10^{6} \mathrm{~m}^{3} \mathrm{~s}^{-1}$ through the Hunter Channel. As a result of our sparse current meter array our total standard error in transport is
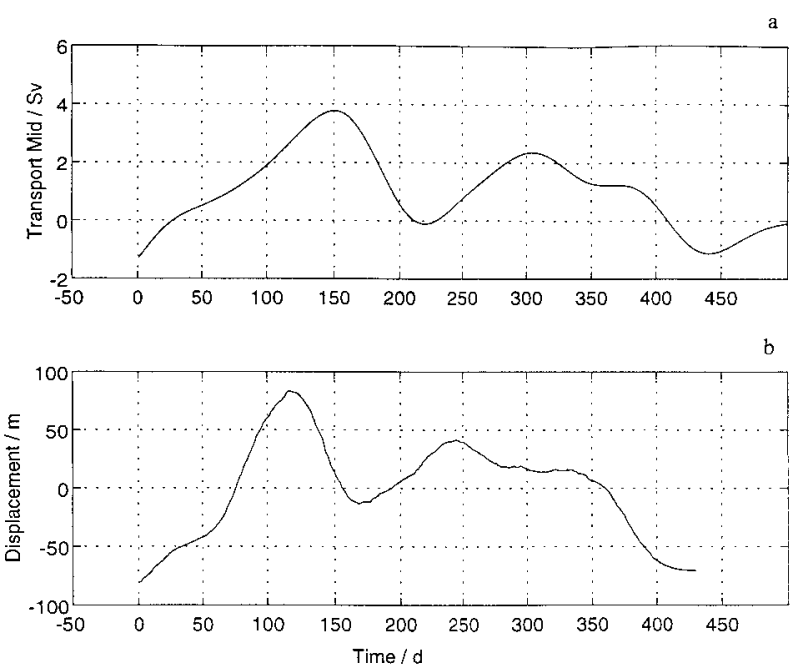

FIG. 15. Low-passed filtered transport (a) through the middle section of the Hunter Channel (see Fig. 11a). Difference (b) of time series of the height of the $0.9^{\circ} \mathrm{C}$ isotherm between $\mathrm{H} 4$ and $\mathrm{H} 5$. about $2 \frac{1}{2}$ times larger than that obtained by Rudnick (1997) for the Samoan Passage.

\section{Discussion and summary}

It was our primary objective to confirm and quantify the mean equatorward flow of Antarctic Bottom Water and its fluctuations through the Hunter Channel. Our observations are based on two well-sampled hydrographic sections and for the first time on direct longterm records from moored current meters and thermistor chains.

There is clear evidence in the Hunter Channel for a similar trend towards higher bottom-water temperatures as reported from the Vema Channel (Zenk and Hogg 1996; Hogg and Zenk 1997). Event-controlled current reversals can advect heat from the Brazil Basin into the Argentine Basin. Comparable, but less frequent, reversals had been reported from the Vema region (Hogg et al. 1982) and they bring into question the representativeness of snapshot hydrographic sections especially when undersampled as in M28. Nevertheless, $89 \%$ of the time the transport of Antarctic Bottom Water through the Hunter Channel is equatorward.

From the difference in height of the $0.9^{\circ} \mathrm{C}$ surface at the two thermistor chains moored on either side of the central portion of the channel (as shown in Fig. 9), a time series of isotherm slope variability was inferred and compared with the recorded transport series (Fig. 
15). The displacement anomaly and the transport are highly correlated although with a time lag of about one month perhaps resulting from frictionally induced deviations from the geostrophic balance. With such a short time series, this lag is not statistically significant.

Major uncertainties in the transport calculations are caused by the spatial resolution of our mooring array. Even the bottom topography, especially with respect to sills, is far less surveyed than elsewhere in comparable channels of the South Atlantic. The Hunter Channel is one order of magnitude wider than the Vema Channel or the Romanche Fracture Zone. No along-axis observations are available from which one could infer the impact of entrainment of overlying NADW on transports. Mercier and Speer (1998) discussed this problem for their equatorial channels and estimate a factor of 2 that could modify the effective throughflow, depending on the position of the current meter array relative to the sill.

How does our equatorward bottom-water export compare with previous estimates? Reid (1989) estimated a mass flux of about $1.8 \times 10^{6} \mathrm{~m}^{3} \mathrm{~s}^{-1}$ through Hunter Channel. In his definition this number includes the region "between Rio Grande Rise and the Mid-Atlantic Rise" at $32^{\circ} \mathrm{S}$ without further specifications. A more recent and highly resolved transport estimate of $0.7 \times$ $10^{6} \mathrm{~m}^{3} \mathrm{~s}^{-1}$ published by Speer et al. (1992) for the inner Hunter Channel is about $40 \%$ of Reid's earlier number. Both studies are based on quasi-synoptic geostrophic sections.

Here we have calculated a mean of $2.92( \pm 1.24) \times$ $10^{6} \mathrm{~m}^{3} \mathrm{~s}^{-1}$. Our new mass flux number for the Hunter Channel is based on long-term direct current observations with moored instruments. It is strikingly higher than those in the two realizations by the dynamical method used by Reid (1989) and Speer et al. (1992). Considering the observed frequency distributions of the Hunter throughflow (Fig. 13c) together with the stabilization time scale of $>200$ d (Fig. 13b), we assume this number to be closer to a significant mean.

Our results add new weight to the relative importance of the Hunter Channel inflow when compared with the latest contribution of the Vema Channel (Hogg et al. 1999). Nearly one half of the deep inflow into the Brazil Basin between the Brazilian continental slope and the Mid-Atlantic Ridge is estimated to be transported through the Hunter Channel. After investigation of the current variability, we confirm earlier concerns that no single geostrophic calculation can replace a long-term mean flow estimate. In the given case, minimum record lengths of $200 \mathrm{~d}$ are required for achieving the necessary transport stability. The unknown pathways of bottomwater import through the Hunter Channel, its mixing with Circumpolar Deep Water, its effects on abyssal upwelling (Morris et al. 1997), and its contribution on the export at equatorial latitudes (Hall et al. 1997; Mercier and Speer 1998; Rhein et al. 1998) deserve further attention.
Acknowledgments. The authors appreciated the able assistance of the captains and the crews of the Meteor during deployment and recovery cruises. We further acknowledge the help of the marine physics department at IfM Kiel and the assistance of the bathymetric group at the AWI Bremerhaven. We enjoyed the helpful discussions with K. Speer during the design and field phases of the experiment in the Hunter Channel. P. Heil and C. Tietze assisted in data processing. Valuable comments on the manuscript by Jack Whitehead are appreciated. This work was supported by the Deutsche Forschungsgemeinschaft (Grants Si 111/38-1, Si 111/39-1, Ze 145/7-1) and by the Bundesministerium für Bildung, Wissenschaft, Forschung und Technologie, Bonn, under Contract 03F0535A. The U.S. contribution was funded by the U.S. National Science Foundation through Grants OCE-90-04396 and OCE-94-15509.

\section{REFERENCES}

Bendat, J. S., and A. G. Piersol, 1966: Measurement and Analysis of Random Data. J. Wiley, 390 pp.

Broecker, W. S., T. Takahashi, and Y.-H. Li, 1976: Hydrography of the central Atlantic: I. The two degree discontinuity. Deep-Sea Res., 23, 1083-1104.

Burckle, L., and P. E. Biscaye, 1971: Sediment transport by Antarctic Bottom Water through the eastern Rio Grande Rise. Geol. Soc. Amer. Abstr. Progr., 3, 518-519.

Cherkis, N. Z., H. S. Fleming, and J. M. Brozena, 1989: Bathymetry of the South Atlantic Ocean, $3^{\circ} \mathrm{S}-40^{\circ} \mathrm{S}$. Geological Society of America, Map and Chart Series-MCH 069.

Hall, M., M. McCartney, and J. A. Whitehead, 1997: Antarctic Bottom Water flux in the equatorial western Atlantic. J. Phys. Oceanogr., 27, 1903-1927.

Hogg, N. G., and W. Zenk, 1997: Long-period changes in the bottom water flowing through Vema Channel. J. Geophys. Res., 102, $15639-15646$.

— transport and modification of Antarctic Bottom Water in the Vema Channel. J. Mar. Res., 40 (Suppl.), 231-263.

- W. B. Owens, G. Siedler, and W. Zenk, 1996: Circulaton in the deep Brazil Basin. The South Atlantic: Present and Past Circulation, G. Wefer et al., Eds., Springer Verlag, 355-361.

—, G. Siedler, and W. Zenk, 1999: Circulation and variability at the southern boundary of the Brazil Basin. J. Phys. Oceanogr., 29, 145-157.

Holfort, J., 1994: Großräumige Zirkulation und meridionale Transporte im Südatlantik. Ph.D. dissertation, University of Kiel, 96 pp. [Available from Institut für Meereskunde, Düstembrooker Weg 20, 24105 Kiel, Germany.]

Johnson, G. C., and T. B. Sanford, 1992: Secondary circulation in the Faroe Bank Channel outflow. J. Phys. Oceanogr., 22, 927933.

Jungclaus, J. H., and M. Vanicek, 1999: Frictionally modified flow in a deep ocean channel: Application to the Vema Channel. $J$. Geophys. Res., in press.

Limmer, R., 1987: The man who became president. Hunter Mag., 6, $12-16$.

Mercier, H., and K. G. Speer, 1998: Transport of bottom water in the Romanche Fracture Zone and the Chain Fracture Zone. J. Phys. Oceanogr., 28, 779-790.

,-- , and J. Honnorez, 1997: Flow pathways of bottom water through the Romanche and Chain Fracture Zones. Deep-Sea Res., 41, 1457-1477.

Morris, M., N. Hogg, and W. B. Owens, 1997: Diapycnal mixing 
estimated from advective budgets in the deep Brazil Basin. WOCE Newslett., 28, 23-25.

Pätzold, J., K. Heidland, W. Zenk, and G. Siedler, 1996: On bathymetry of the Hunter Channel. The South Atlantic: Present and Past Circulation, G. Wefer et al., Eds., Springer Verlag, 355361.

Polzin, K. L., J. M. Toole, J. R. Ledweel, and R. W. Schmitt, 1997: Spatial variability of turbulent mixing in the abyssal ocean. Science, 276, 93-96.

Reid, J. L., 1989: On the total geostrophic circulation of the South Atlantic Ocean: Flow patterns, tracers and transports. Progress in Oceanography, Vol. 23, Pergamon, 149-244.

—, W. D. Nowlin, and W. C. Patzert, 1977: On the characteristics and circulation in the southwestern Atlantic Ocean. J. Phys. Oceanogr., 7, 62-91.

Rhein, M., L. Stramma, and G. Krahmann, 1998: The spreading of Antarctic Bottom Water in the Tropical Atlantic. Deep-Sea Res. $45,507-527$.

Rudnick, D. L., 1997: Direct velocity measurements in the Samoan Passage. J. Geophys. Res., 102, 3293-3302.

Saunders, P. M., and J. W. Cherriman, 1983: Abyssal temperature measurements with Aanderaa current meters. Deep-Sea Res., 30, 663-667.

Schulz, H. D., P. Stoffers, J. Pätzold, and G. Fischer, 1999: Geo Bremen/GPI Kiel Südatlantik 1998, Reise Nr. 41, Meteor-Berichte, Universität Hamburg, 99-3, in press.

Siedler, G., and W. Zenk, 1992: WOCE Südatlantik 1991, Reise Nr. 15, 30. Dezember 1990 - 23. März 1991. Meteor-Berichte, Universität Hamburg, 92-1, $126 \mathrm{~S}$.

- W. Balzer, T. J. Müller, R. Onken, M. Rhein, and W. Zenk, 1993: WOCE South Atlantic 1992, Cruise No. 22, 22 September 1992-31 January 1993. Meteor-Berichte, Universität Hamburg, 93-5, $131 \mathrm{~S}$.
Smith, W. H. F., and D. T. Sandwell, 1997: Global sea floor topography from satellite altimetry and ship depth soundings. Science, 277, $1956-1962$.

Speer, K. G., and W. Zenk, 1993: The flow of Antarctic Bottom Water into the Brazil Basin. J. Phys. Oceanogr., 23, 2667-2682.

,-- , G. Siedler, J. Pätzold, and C. Heidland, 1992: First resolution of flow through the Hunter Channel in the South Atlantic. Earth Planet. Sci. Lett., 113, 287-292.

Vangriesheim, A., 1980: Antarctic bottom water flow through the Vema fracture zone. Oceanol. Acta, 3, 199-207.

Whitehead, J. A., 1998: Topographic control of oceanic flows in deep passages and straits. Rev. Geophys., 36, 423-440.

Zangenberg, N., and G. Siedler, 1998: The path of the North Atlantic Deep Water in the Brazil Basin. J. Geophys. Res., 103 (C3), 5419-5426.

Zemba, J. C., 1991: The structure and transport of the Brazil Current between $27^{\circ}$ and $36^{\circ} \mathrm{S}$. Ph.D. dissertation, WHOI-91-37, $160 \mathrm{pp}$. [Available from Institut für Meereskunde, Düstenbrooker Weg 20, 24105 Kiel, Germany.]

Zenk, W., and T. J. Müller, 1995: WOCE studies in the South Atlantic. Cruise No. 28, 9 March-14 June 1994. Meteor-Berichte, Universität Hamburg, 95-1, 193 pp. [Available from Woods Hole Oceanographic Institution, Woods Hole, MA 02543-1541.]

— Water flowing into the Brazil Basin. Deep-Sea Res. I, 43, 14611473.

_ Sill. Deep-Sea Res., 40, 1925-1933.

_ M. Manicek, D. Carlsen, and A. Pinck, 1996: 4.1 Hydrographic observations, 9-48. Report and preliminary results of Meteorcruise M34/3, Walvis Bay - Recife, 21.2.-17.3.1996. Berichte, Fachbereich Geowissenschaften, Universität Bremen, No. 79, Bremen, Germany. 